\title{
Serum Carboxy-Terminal Telopeptide of Type I Collagen (ICTP) Predicts Cardiac Events in Chronic Heart Failure Patients With Preserved Left Ventricular Systolic Function
}

\author{
Tatsuro Kitahara, MD; Yasuchika Takeishi, MD; Takanori Arimoto, MD; \\ Takeshi Niizeki, MD; Yo Koyama, MD; Toshiki Sasaki, MD; Satoshi Suzuki, MD; \\ Naoki Nozaki, MD; Osamu Hirono, MD; Joji Nitobe, MD; \\ Tetsu Watanabe, MD; Isao Kubota, MD
}

\begin{abstract}
Background Clinical markers to predict adverse outcome have not yet been established for patients with preserved left ventricular (LV) systolic function. The present study was designed to examine whether carboxy-terminal telopeptide of type I collagen (ICTP), a marker of collagen degradation, is useful for determining the prognosis of such patients.

Methods and Results Serum levels of ICTP were measured at admission in 156 consecutive patients hospitalized for chronic heart failure (CHF). Patients were divided into 2 groups based on the LV ejection fraction (LVEF): reduced LV systolic function group $(\mathrm{LVEF}<50 \%, \mathrm{n}=92)$ and preserved LV systolic function group ( $\mathrm{LVEF} \geq 50 \%, \mathrm{n}=64)$. In preserved LV systolic function group, cardiac event-free rates were significantly lower in high ICTP group than in low ICTP group $(\mathrm{p}<0.001)$. The area under the receiver operating characteristic curve of ICTP in the preserved LV systolic function group was markedly larger than that in the reduced LV systolic function group. Cox multivariate analysis also revealed that ICTP was an independent predictor of cardiac events in the preserved LV systolic function group.

Conclusion Serum ICTP level is highly reliable for risk stratifying CHF patients with preserved LV systolic function. (Circ J 2007; 71: 929-935)
\end{abstract}

Key Words: Carboxy-terminal telopeptide of type I collagen (ICTP); Diastolic HF; Prognosis

A number of epidemiological studies have documented that a high proportion of patients with chronic heart failure (CHF) has preserved left ventricular (LV) systolic function, and this condition is commonly referred to as diastolic heart failure (HF)! Excessive LV hypertrophy and development of fibrosis are associated with the onset of diastolic HF. The myocardial extracellular matrix is thought to play an important part in the pathogenesis of ventricular dilation, and the fibrillar extracellular matrix is mainly composed of types I and III fibrillar collagens forming a 3-dimensional framework, stabilizing the ventricular geometry and preserving the alignment of cardiomyocytes, which is important for normal LV function?

Although morbidity and mortality rates in diastolic HF are high! most of the previous studies have focused on systolic HF, and clinical markers to predict adverse outcome have not yet been established for diastolic HF. Therefore, the aims of the present study were (1) to characterize the clinical features of CHF patients with preserved LV systolic function, and (2) to examine whether the carboxy-terminal

(Received February 8, 2007; revised manuscript received March 6, 2007; accepted March 20, 2007)

Department of Cardiology, Pulmonology, and Nephrology, Yamagata University School of Medicine, Yamagata, Japan

Mailing address: Yasuchika Takeishi, MD, Department of Cardiology, Pulmonology, and Nephrology, Yamagata University School of Medicine, 2-2-2 Iida-Nishi, Yamagata 990-9585, Japan. E-mail: takeishi@med.id.yamagata-u.ac.jp telopeptide of type I collagen (ICTP), a marker of collagen degradation, can reliably risk stratify CHF patients with preserved LV systolic function.

\section{Methods}

Subjects and Study Design

We prospectively studied 156 consecutive patients (97 men, 59 women; mean age, $68 \pm 13$ years, range $24-93$ ) who were admitted to the Yamagata University Hospital from June 1996 to February 2005 for the treatment of worsening $\mathrm{CHF}$ or for diagnosis and pathophysiological investigations or for therapeutic evaluation of CHF. The diagnosis of CHF was based on a history of dyspnea and symptomatic exercise intolerance with signs of pulmonary congestion or peripheral edema on chest X-ray, echocardiography or radionuclide ventriculography ${ }^{3-6}$ Exclusion criteria were clinical or electrocardiographic evidence suggestive of acute coronary syndrome within the 3 months preceding admission, severe valvular heart disease, renal insufficiency characterized by a serum creatinine concentration $>2.5 \mathrm{mg} / \mathrm{dl}$, and active hepatic or pulmonary diseases ${ }^{3-6}$ In addition, we excluded patients with aortitis, collagen diseases, malignant diseases, and osteoporosis, which might have influenced the serum ICTP value. Informed consent was given by all patients before participation in the study, and the study protocol was approved by the institution's Human Investigations Committee. 
Table 1 Clinical Characteristics of 156 Patients With CHF

\begin{tabular}{|c|c|}
\hline & All patients $(n=156)$ \\
\hline Age (years) & $68 \pm 13$ \\
\hline Female & $59(38 \%)$ \\
\hline NYHA class (II/III/IV) & $90 / 49 / 17$ \\
\hline Hypertension & $84(54 \%)$ \\
\hline Hyperlipidemia & $34(22 \%)$ \\
\hline Diabetes mellitus & $41(26 \%)$ \\
\hline Atrial fibrillation & $33(21 \%)$ \\
\hline \multicolumn{2}{|l|}{ Etiology of $\mathrm{CHF}$} \\
\hline Dilated cardiomyopathy & $57(37 \%)$ \\
\hline Ischemic heart disease & $52(33 \%)$ \\
\hline Hypertensive heart disease & $29(19 \%)$ \\
\hline Hypertrophic cardiomyopathy & $3(2 \%)$ \\
\hline Others & $15(9 \%)$ \\
\hline \multicolumn{2}{|l|}{ Laboratory data } \\
\hline $\mathrm{Na}(\mathrm{mmol} / \mathrm{L})$ & $140 \pm 3$ \\
\hline Uric acid $(\mathrm{mg} / \mathrm{dl})$ & $6.0 \pm 2.0$ \\
\hline Creatinine $(\mathrm{mg} / \mathrm{dl})$ & $0.9 \pm 0.3$ \\
\hline$B N P(p g / m l)$ & $531 \pm 675$ \\
\hline $\log _{10} B N P$ & $2.29 \pm 0.73$ \\
\hline $\operatorname{ICTP}(n g / m l)$ & $6.0 \pm 3.8$ \\
\hline \multicolumn{2}{|l|}{ Echocardiography } \\
\hline $\operatorname{LVEDD}(\mathrm{mm})$ & $55 \pm 10$ \\
\hline $\operatorname{LVEF}(\%)$ & $45 \pm 20$ \\
\hline E/A ratio & $1.4 \pm 1.6$ \\
\hline E wave deceleration (ms) & $202 \pm 98$ \\
\hline \multicolumn{2}{|l|}{ Medications at admission } \\
\hline ACE inhibitors and/or ARBs & $95(61 \%)$ \\
\hline$\beta$-blockers & $38(24 \%)$ \\
\hline Ca-antagonists & $40(26 \%)$ \\
\hline Diuretics & $89(57 \%)$ \\
\hline Spironolactone & $40(26 \%)$ \\
\hline Digoxin & $44(28 \%)$ \\
\hline \multicolumn{2}{|l|}{ Medications at discharge } \\
\hline$A C E$ inhibitors and/or $A R B s$ & $107(69 \%)$ \\
\hline$\beta$-blockers & $64(41 \%)$ \\
\hline Ca-antagonists & $45(29 \%)$ \\
\hline Diuretics & $97(62 \%)$ \\
\hline Spironolactone & $43(28 \%)$ \\
\hline Digoxin & $45(29 \%)$ \\
\hline
\end{tabular}

CHF, chronic heart failure; NYHA, New York Heart Association; BNP, brain natriuretic peptide; ICTP, carboxy-terminal telopeptide of type I collagen; $L V E D D$, left ventricular dimension at end-diastole; LVEF, left ventricular ejection fraction; ACE, angiotensin-converting enzyme; $A R B$, angiotensin-II receptor blocker.

Clinical characteristics of the study subjects are listed in Table 1. The functional severity of CHF was New York Heart Association (NYHA) class II in 90, class III in 49, and class IV in 17 patients. The etiologies of CHF were dilated cardiomyopathy in $57(37 \%)$, ischemic heart disease in 52 (33\%), hypertensive heart disease in $29(19 \%)$, hypertrophic cardiomyopathy in $3(2 \%)$, and others in 15 patients $(9 \%)$. A history of hypertension was considered present if the patient was currently, or previously, on medical therapy for high blood pressure. A diagnosis of diabetes and hyperlipidemia was obtained from medical records or patient history ${ }^{3-6}$

Blood samples were obtained at admission for measurement of serum ICTP concentrations. Physicians were kept unaware of the results of the biochemical markers, and optimal medical therapy was performed independently, based on improvement in symptoms, physical examination findings, and pulmonary congestion on chest X-ray.

\section{Endpoints and Follow-up}

No patients were lost to follow-up (mean follow-up 643 \pm 354 days, range 5-1,095 days) after admission. Events were centrally adjudicated using medical records, autopsy reports, death certificates, and witness statements. The endpoints, which were judged independently by researchers, were (1) cardiac death, defined as death from worsening HF or sudden cardiac death, and (2) worsening HF requiring readmission ${ }^{3-6}$ Sudden cardiac death was defined as death without definite premonitory symptoms or signs and was established by the attending physician.

\section{Assay of ICTP Concentrations}

Venous blood samples were immediately centrifuged at $2,500 \mathrm{G}$ for $15 \mathrm{~min}$ at $4^{\circ} \mathrm{C}$. The clarified serum samples were frozen, stored at $-80^{\circ} \mathrm{C}$, and thawed just before assay. ICTP concentrations were determined by radioimmunoassay as previously reported using a polyclonal antibody specifically directed against the ICTP (Orion Diagnostica, Finland)? The intra- and interassay variations for determining ICTP were $<8 \%$. The sensitivity (lower detection limit) was $0.5 \mathrm{ng} / \mathrm{ml}$.

\section{Echocardiography}

Two-dimensional echocardiography was performed within 1 week after admission, using routine standard care by experts unaware of the study data. LV dimensions were measured by M-mode tracing, and the LV ejection fraction (LVEF) was calculated based on Simpson's rule. Pulsed Doppler wave examination of mitral inflow was performed in each subject as previously reported?

\section{Statistical Analysis}

Results are presented as mean value \pm SD for continuous variables and as the percentage of total patients for categorical variables. The t-test and chi-square test were used for comparison of continuous and categorical variables, respectively. The value below the lower detection limit of the assay was defined as 0 . A Cox proportional hazard analysis was performed to determine the independent predictor of cardiac events for the entire population. Significant variables selected in the univariate analysis were entered into the multivariate analysis. The cardiac event-free curve was computed according to the Kaplan-Meier method and compared by the log-rank test. The receiver operating characteristic (ROC) curves were constructed to evaluate the area under the ROC curves (AUC). Statistical significance was determined at $\mathrm{p}<0.05$. Statistical analysis was performed with a standard statistical program package (StatView, version 5.0, SAS Institute Inc, Cary, NC, USA).

\section{Results}

Table 1 summarizes the clinical backgrounds and characteristics of all patients. A simple linear regression analysis showed that serum ICTP concentrations were weakly correlated with the plasma brain natriuretic peptide (BNP) concentrations $(\mathrm{R}=0.307, \mathrm{p}<0.001)$.

All patients were divided into 4 groups based on the ICTP value: $1^{\text {st }}$ quartile $(1.2-3.4 \mathrm{ng} / \mathrm{ml}, \mathrm{n}=40), 2^{\text {nd }}$ quartile (3.5-4.6ng/ml, $\mathrm{n}=39), 3^{\text {rd }}$ quartile $(4.7-7.2 \mathrm{ng} / \mathrm{ml}, \mathrm{n}=39)$, and $4^{\text {th }}$ quartile $(7.3-19.3 \mathrm{ng} / \mathrm{ml}, \mathrm{n}=38)$. Table 2 summarizes the comparisons of the clinical characteristics of the 4 groups. NYHA functional class was more severe in the $3^{\text {rd }}$ and $4^{\text {th }}$ quartiles $(\mathrm{p}<0.05)$. There were 50 cardiac events (32\%), including 19 cardiac deaths and 31 readmissions for worsening $\mathrm{HF}$, during the follow-up period. The causes of cardiac death were worsening $\mathrm{CHF}$ in 13 patients and fatal 
Table 2 Comparisons of Clinical Characteristics Among 4 Groups

\begin{tabular}{|c|c|c|c|c|}
\hline & $\begin{array}{c}1^{\text {st }} \text { quartile } \\
(n=40)\end{array}$ & $\begin{array}{c}2^{\text {nd }} \text { quartile } \\
(n=39)\end{array}$ & $\begin{array}{c}3^{\text {rd }} \text { quartile } \\
\quad(n=39)\end{array}$ & $\begin{array}{c}4^{\text {th }} \text { quartile } \\
(n=38)\end{array}$ \\
\hline Age & $62 \pm 12$ & $67 \pm 12$ & $73 \pm 12 * \#$ & $71 \pm 14^{*}$ \\
\hline Female & $11(19 \%)$ & $18(31 \%)$ & $18(31 \%)$ & $12(20 \%)$ \\
\hline NYHA class & $2.2 \pm 0.5$ & $2.4 \pm 0.5$ & $2.8 \pm 0.8^{*, \#}$ & $2.8 \pm 0.7^{*, \#}$ \\
\hline Hypertension & $19(48 \%)$ & $22(56 \%)$ & $19(49 \%)$ & $24(63 \%)$ \\
\hline Hyperlipidemia & $10(25 \%)$ & $10(26 \%)$ & $5(13 \%)$ & $9(24 \%)$ \\
\hline Diabetes mellitus & $6(15 \%)$ & $13(33 \%)$ & $10(26 \%)$ & $12(32 \%)$ \\
\hline Atrial fibrillation & $3(8 \%)$ & $10(26 \%)$ & $16(41 \%)$ & $4(11 \%)$ \\
\hline \multicolumn{5}{|l|}{ Etiology of chronic heart failure } \\
\hline Dilated cardiomyopathy & $11(28 \%)$ & $18(46 \%)$ & $15(38 \%)$ & $13(34 \%)$ \\
\hline Ischemic heart disease & $18(45 \%)$ & $10(26 \%)$ & $11(28 \%)$ & $13(34 \%)$ \\
\hline Hypertensive heart disease & $7(18 \%)$ & $6(15 \%)$ & $7(18 \%)$ & $9(24 \%)$ \\
\hline Hypertrophic cardiomyopathy & $1(2 \%)$ & $1(3 \%)$ & $0(0 \%)$ & $1(3 \%)$ \\
\hline Others & $3(7 \%)$ & $4(10 \%)$ & $6(15 \%)$ & $2(5 \%)$ \\
\hline \multicolumn{5}{|l|}{ Laboratory data } \\
\hline $\mathrm{Na}(\mathrm{mmlo} / \mathrm{L})$ & $141 \pm 2$ & $141 \pm 2$ & $140 \pm 4$ & $139 \pm 4 *$ \\
\hline Uric acid $(m g / d l)$ & $5.5 \pm 1.8$ & $5.8 \pm 2.0$ & $6.3 \pm 2.0$ & $6.4 \pm 2.2$ \\
\hline Creatinine $(\mathrm{mg} / \mathrm{dl})$ & $0.7 \pm 0.2$ & $0.8 \pm 0.2$ & $0.9 \pm 0.2^{*, \#}$ & $1.2 \pm 0.5^{*, \#}$ \\
\hline$B N P(\mathrm{pg} / \mathrm{ml})$ & $170 \pm 250$ & $367 \pm 494$ & $834 \pm 868^{*, \#}$ & $765 \pm 706^{* \#}$ \\
\hline $\log _{10} B N P$ & $1.8 \pm 0.6$ & $2.1 \pm 0.7$ & $2.6 \pm 0.7^{*, \#}$ & $2.6 \pm 0.5 *$ \\
\hline \multicolumn{5}{|l|}{ Echocardiography } \\
\hline $\operatorname{LVEDD}(\mathrm{mm})$ & $52 \pm 8$ & $55 \pm 10$ & $55 \pm 12$ & $58 \pm 10^{*}$ \\
\hline LVEF (\%) & $51 \pm 20$ & $48 \pm 20$ & $43 \pm 18$ & $39 \pm 19 *, \#$ \\
\hline E/A ratio & $0.9 \pm 0.5$ & $2.0 \pm 2.8^{*}$ & $1.5 \pm 1.0$ & $1.4 \pm 1.2$ \\
\hline E wave deceleration ( $\mathrm{ms}$ ) & $205 \pm 62$ & $206 \pm 80$ & $165 \pm 57$ & $238 \pm 168^{\dagger}$ \\
\hline
\end{tabular}

${ }^{*} p<0.05$ vs $1^{\text {st }}$ quartile, ${ }^{\#} p<0.05$ vs $2^{\text {nd }}$ quartile, and ${ }^{\dagger} p<0.05$ vs $3^{\text {rd }}$ quartile. Abbreviations as in Table 1.

ICTP levels: $1^{\text {st }}$ quartile $(1.2-3.4 \mathrm{ng} / \mathrm{ml})$, $2^{\text {nd }}$ quartile $(3.5-4.6 \mathrm{ng} / \mathrm{ml}), 3^{\text {rd }}$ quartile $(4.7-7.2 \mathrm{ng} / \mathrm{ml})$, and $4^{\text {th }}$ quartile $(7.3-19.3 \mathrm{ng} / \mathrm{ml})$.

acute myocardial infarction in 6 patients. Cardiac event rates significantly increased from the $1^{\text {st }}$ to $4^{\text {th }}$ quartile $\left(1^{\text {st }}\right.$ quartile $7 \%, 2^{\text {nd }}$ quartile $21 \%, 3^{\text {rd }}$ quartile $44 \%$, and $4^{\text {th }}$ quartile $58 \%$, $\mathrm{p}<0.0001)$. Kaplan-Meier survival curve analysis clearly demonstrated that event-free rates were significantly lower in the highest $4^{\text {th }}$ quartile of ICTP concentration compared with the other 3 groups (Fig 1).

Next, all patients were divided into 2 groups based on the LVEF on echocardiography: reduced LV systolic function group (LVEF $<50 \%, \mathrm{n}=92$ ) and preserved LV systolic function group (LVEF $\geq 50 \%, n=64$ ). Table 3 shows the comparison of the clinical backgrounds and characteristics of the 2 groups. The reduced LV systolic function group had a more severe NYHA functional class $(\mathrm{p}<0.01)$ and higher concentrations of uric acid $(\mathrm{p}<0.001)$, creatinine $(\mathrm{p}<0.05)$ and BNP $(\mathrm{p}<0.0001)$, a larger LV end-diastolic dimension $(\mathrm{p}<0.0001)$, and higher E/A ratio $(\mathrm{p}<0.01)$ than the preserved LV systolic function group. There were more patients with dilated cardiomyopathy in the reduced LV systolic function group $(\mathrm{p}<0.0001)$. In contrast, patients with hypertension $(\mathrm{p}<0.05)$ and hypertensive heart disease $(p<0.0001)$ were more common in the preserved LV systolic function group. Concentration of ICTP was not significantly different between the reduced and preserved LV systolic function groups. As shown in Fig 2, Kaplan-Meier analysis demonstrated that cardiac event-free rates were significantly lower in the reduced LV systolic function group than in the preserved LV systolic function group (39\% vs $22 \%, \mathrm{p}=0.0134)$.

Next, we examined the predictive value of ICTP separately in the reduced and preserved LV systolic function groups. Patients in these function groups were divided into 2 groups based on the median value of ICTP for all patients ( $4.8 \mathrm{ng} / \mathrm{ml})$. In the reduced LV systolic function group, Kaplan-Meier analysis demonstrated that the cardiac eventfree rates were not different between the high ICTP group (ICTP $>4.8 \mathrm{ng} / \mathrm{ml}$ ) and the low ICTP group (ICTP $<4.8 \mathrm{ng} / \mathrm{ml}$ )

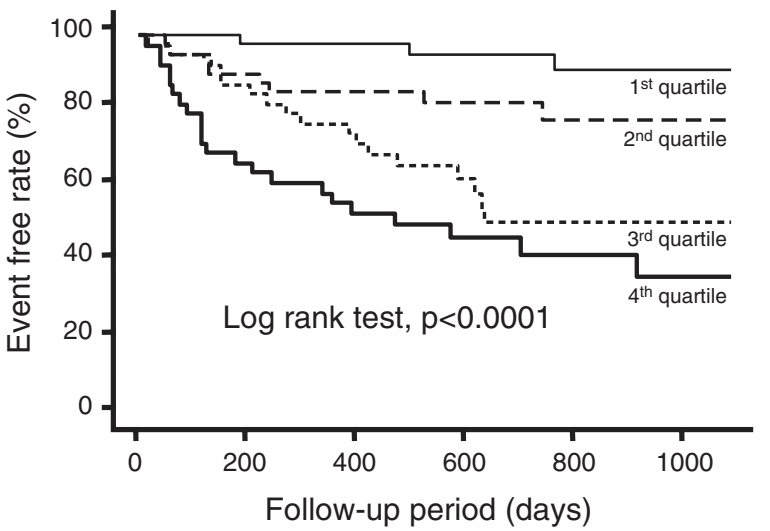

Fig 1. Kaplan-Meier analysis of cardiac event-free rate in patients with chronic heart failure stratified into 4 groups based on ICTP values: $1^{\text {st }}$ quartile $(1.2-3.4 \mathrm{ng} / \mathrm{ml}, \mathrm{n}=40), 2^{\text {nd }}$ quartile $(3.5-4.6 \mathrm{ng} / \mathrm{ml}, \mathrm{n}=39)$, $3^{\text {rd }}$ quartile $(4.7-7.2 \mathrm{ng} / \mathrm{ml}, \mathrm{n}=39)$, and $4^{\text {th }}$ quartile $(7.3-19.3 \mathrm{ng} / \mathrm{ml}$, $\mathrm{n}=38$ ). ICTP, carboxy-terminal telopeptide of type I collagen.

(Fig 3A). However in the preserved LV systolic function group, the cardiac event-free rates were significantly lower in the high ICTP group (ICTP $>4.8 \mathrm{ng} / \mathrm{ml}$ ) than in the low ICTP group (ICTP $<4.8 \mathrm{ng} / \mathrm{ml}$ ) as shown in Fig 3B (p< $0.001)$.

The ROC curves for ICTP to predict cardiac events at 36 months after admission in the reduced and preserved LV systolic function groups are shown in Fig 4. The AUC in the preserved LV systolic function group was markedly larger than that in the reduced LV systolic function group ( 0.881 vs 0.653), suggesting that ICTP can predict cardiac event more accurately in the preserved LV systolic function group than in the reduced LV systolic function group.

The ability of prognostic variables to predict cardiac events was examined by univariate and multivariate Cox pro- 
Table 3 Comparisons of Clinical Characteristics Between Patients With Reduced and Preserved LV Systolic Function

\begin{tabular}{|c|c|c|c|}
\hline & Reduced group $(n=92)$ & Preserved group $(n=64)$ & $p$ value \\
\hline Age & $67 \pm 14$ & $71 \pm 11$ & $N S$ \\
\hline Female & $32(35 \%)$ & $27(42 \%)$ & NS \\
\hline NYHA & $2.7 \pm 0.7$ & $2.4 \pm 0.6$ & $<0.01$ \\
\hline Hypertension & $43(47 \%)$ & $41(64 \%)$ & $<0.05$ \\
\hline Hyperlipidemia & $21(23 \%)$ & $13(20 \%)$ & NS \\
\hline Diabetes mellitus & $27(29 \%)$ & $14(22 \%)$ & $N S$ \\
\hline Atrial fibrillation & $18(20 \%)$ & $15(23 \%)$ & NS \\
\hline \multicolumn{4}{|l|}{ Etiology of $\mathrm{CHF}$} \\
\hline Dilated cardiomyopathy & $50(54 \%)$ & $7(11 \%)$ & $<0.0001$ \\
\hline Ischemic heart disease & $31(34 \%)$ & $21(33 \%)$ & $N S$ \\
\hline Hypertensive heart disease & $5(5 \%)$ & $24(38 \%)$ & $<0.0001$ \\
\hline Hypertrophic cardiomyopathy & $1(1 \%)$ & $2(3 \%)$ & NS \\
\hline Others & $5(5 \%)$ & $10(16 \%)$ & $N S$ \\
\hline \multicolumn{4}{|l|}{ Laboratory data } \\
\hline $\mathrm{Na}(\mathrm{mmol} / \mathrm{L})$ & $140 \pm 3$ & $141 \pm 4$ & $N S$ \\
\hline Uric acid $(m g / d l)$ & $6.6 \pm 2.1$ & $5.3 \pm 1.5$ & $<0.001$ \\
\hline Creatinine $(\mathrm{mg} / \mathrm{dl})$ & $1.0 \pm 0.4$ & $0.8 \pm 0.3$ & $<0.05$ \\
\hline$B N P(p g / m l)$ & $719 \pm 735$ & $261 \pm 454$ & $<0.0001$ \\
\hline $\log _{10} B N P$ & $2.58 \pm 0.58$ & $1.87 \pm 0.73$ & \\
\hline $\operatorname{ICTP}(\mathrm{ng} / \mathrm{ml})$ & $6.5 \pm 4.0$ & $5.3 \pm 3.5$ & $N S$ \\
\hline \multicolumn{4}{|l|}{ Echocardiography } \\
\hline $\operatorname{LVEDD}(\mathrm{mm})$ & $60 \pm 9$ & $48 \pm 8$ & $<0.0001$ \\
\hline $\operatorname{LVEF}(\%)$ & $32 \pm 10$ & $66 \pm 10$ & $<0.0001$ \\
\hline E/A ratio & $1.8 \pm 2.0$ & $0.9 \pm 0.4$ & $<0.01$ \\
\hline E wave deceleration & $205 \pm 117$ & $197 \pm 63$ & $N S$ \\
\hline
\end{tabular}

LV, left ventricular. Other abbreviations as in Table1.

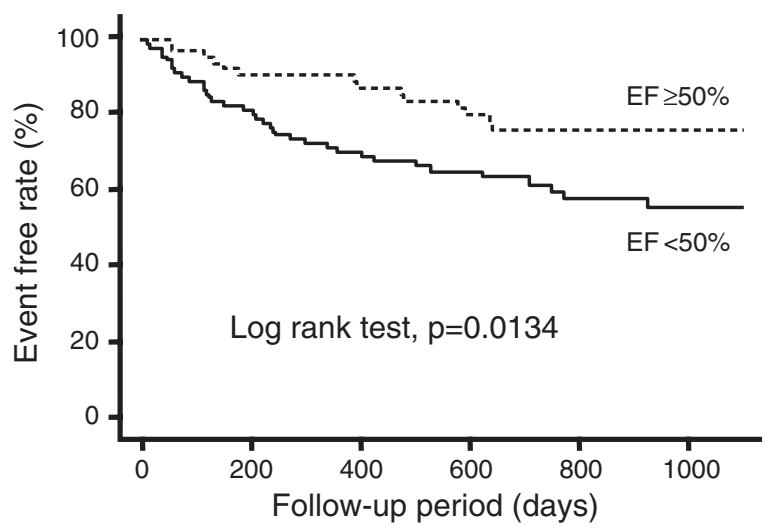

Fig 2. Kaplan-Meier analysis of cardiac event-free rate in patients with chronic heart failure stratified into 2 groups based on the left ventricular ejection fraction (EF) by echocardiography $(\geq 50 \%$ and $<50 \%)$.

portional hazard analyses. In the reduced LV systolic function group, ICTP, common logarithm of BNP, creatinine, NYHA functional class, and age were associated with subsequent cardiac events in the univariate analysis (Table4). Therefore, these 5 variables were entered into the multivari- ate analysis. Creatinine (hazard ratio $1.435,95 \%$ confidence interval (CI) 1.013-2.032, p<0.05) and common logarithm of BNP (hazard ratio 2.928, 95\% CI 1.279-6.702, p<0.05) were independent predictors of cardiac events in the reduced LV function group in the multivariate analysis. Serum ICTP was not an independent predictor of cardiac events in the reduced LV systolic function group.

In the preserved LV systolic function group, ICTP, common logarithm of BNP, creatinine, sodium, atrial fibrillation, NYHA functional class, and age were associated with subsequent cardiac events in the univariate analysis (Table 5), so these 7 variables were entered into the multivariate analysis. Sodium (hazard ratio $0.871,95 \%$ CI $0.76-$ $0.996, \mathrm{p}<0.05$ ) and ICTP (hazard ratio $1.210,95 \%$ CI $1.013-$ $1.446, \mathrm{p}<0.05)$ were independent predictors of cardiac events in the preserved LV systolic function group.

\section{Discussion}

The present study has demonstrated that the ICTP concentration at admission was independently associated with cardiac events in patients hospitalized for CHF, particularly those with preserved LV systolic function.

The 12-kDa ICTP, which results from the cleavage of

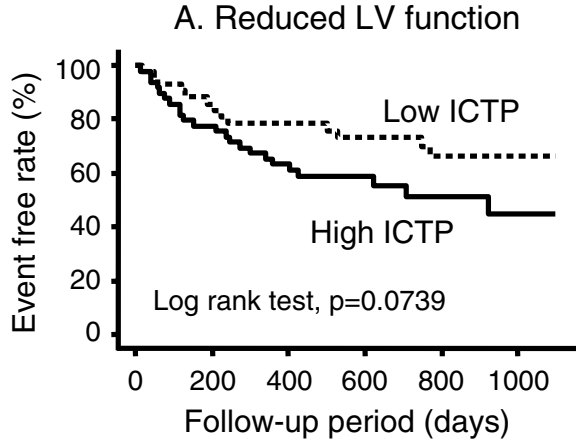

\section{B. Preserved LV function}

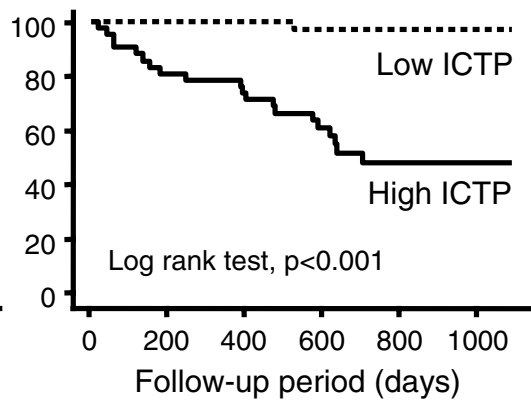

Fig 3. (A) Kaplan-Meier analysis of cardiac event-free rate in the reduced left ventricular (LV) systolic function group stratified into 2 groups based on the median values for carboxy-terminal telopeptide of type I collagen (ICTP): high ICTP $>4.9 \mathrm{ng} / \mathrm{ml}$, low ICTP $\leq 4.9 \mathrm{ng} / \mathrm{ml}$ ). (B) Kaplan-Meier analysis of cardiac event-free rate in the preserved LV systolic function group stratified into 2 groups based on the ICTP median values: high ICTP $>4.2 \mathrm{ng} / \mathrm{ml}$, low ICTP $\leq 4.2 \mathrm{ng} / \mathrm{ml}$ ). 
collagen type I by collagenase, is found in an immunochemically intact form in blood? On the basis of a number of clinical and experimental observations, it has been suggested that the serum concentration of ICTP reflects the rate of extracellular degradation of collagen type I?,10 Diastolic dysfunction refers to an abnormality of LV diastolic relaxation and stiffness. ${ }^{11}$ Myocardial stiffness is determined by ventricular fibrosis, and may be attributed to progressive collagen accumulation and a shift of the collagen phenotype from type III to type $I^{12}$ indicating that the release of ICTP into circulation reflects ventricular fibrosis and myocardial stiffness associated with progression of HF, particularly diastolic dysfunction. In addition, it has been recently reported that the serum levels of ICTP are increased in patients with dilated cardiomyopathy, hypertrophic cardiomyopathy and untreated hypertension compared with normal patients $!^{13-15}$ Some studies have reported that there is a significant correlation between ICTP and the carboxyterminal propeptide of collagen type I (PIPC), a marker of collagen synthesis ${ }^{15}$ Treatment with loop diuretics, ${ }^{16}$ and angiotensin-converting enzyme inhibitors or angiotensin II receptor blockers ${ }^{17}$ decreases the PIPC levels, despite the tendency toward increased ICTP in patients with CHF. The data suggest that these pharmacotherapies shift the balance toward degradation of collagen type I fibers and tend to restore the equilibrium between collagen type I synthesis and degradation, but the degree of increased ICTP is smaller

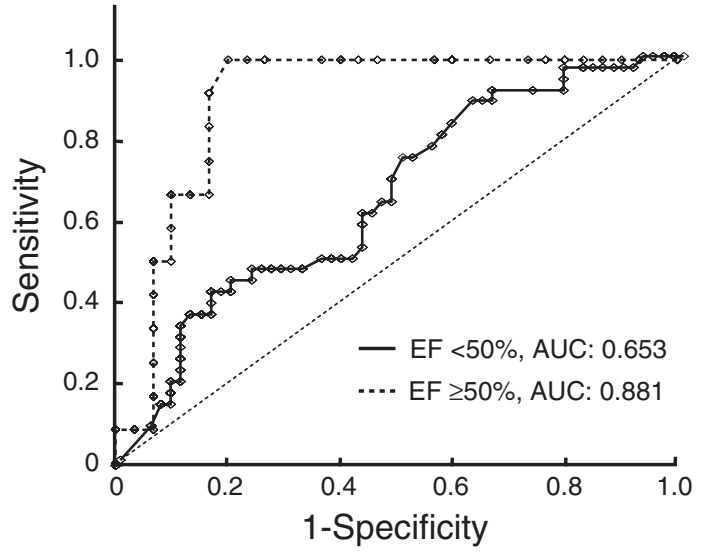

Fig 4. Receiver operating characteristic (ROC) curve analysis. Carboxy-terminal telopeptide of type I collagen in heart failure was evaluated for prediction of cardiac events in both the reduced and preserved left ventricular (LV) systolic function groups at 36 months after admission. Area under the ROC curve (AUC) was larger in the preserved than in the reduced LV systolic function group. EF, ejection fraction.

Table 4 Univariate and Multivariate Cox Hazard Analyses for Predicting Cardiac Events in Reduced LV Systolic Function Group

\begin{tabular}{lccc}
\hline \hline & Hazard ratio & 95\%confidence interval of hazard ratio & $p$ value \\
\hline Univariate analysis & & & \\
Age (per 1 year increases) & 1.029 & $1.002-1.056$ & $<0.05$ \\
NYHA functional class & 1.675 & $1.085-2.584$ & $<0.05$ \\
Creatinine (per 1 SD increases) & 1.680 & $1.314-2.149$ & $<0.001$ \\
Loglo BNP & 3.939 & $1.899-8.171$ & $<0.001$ \\
ICTP & 1.096 & $1.023-1.173$ & $<0.01$ \\
Multivariate analysis & & & $N S$ \\
Age (per 1 year increases) & 1.006 & $0.980-1.033$ & $N S$ \\
NYHA functional class & 1.096 & $0.620-1.938$ & $<0.05$ \\
Creatinine (per 1 SD increases) & 1.435 & $1.013-2.032$ & $<0.05$ \\
Logio BNP & 2.928 & $1.279-6.702$ & $N S$ \\
ICTP & 0.993 & $0.894-1.104$ & \\
\hline
\end{tabular}

Abbreviations as in Tables 1,3.

Table 5 Univariate and Multivariate Cox Hazard Analyses for Predicting Cardiac Events in Preserved LV Systolic Function Group

\begin{tabular}{|c|c|c|c|}
\hline & Hazard ratio & 95\% confidence interval of hazard ratio & $p$ value \\
\hline \multicolumn{4}{|l|}{ Univariate analysis } \\
\hline Age (per 1 year increases) & 1.083 & $1.015-1.156$ & $<0.05$ \\
\hline NYHA functional class & 4.524 & $2.236-9.153$ & $<0.0001$ \\
\hline Creatinine (per 1 SD increases) & 1.857 & $1.200-2.875$ & $<0.01$ \\
\hline $\mathrm{Na}$ & 0.818 & $0.739-0.906$ & $<0.001$ \\
\hline $\log _{10} B N P$ & 4.650 & $1.958-11.043$ & $<0.001$ \\
\hline ICTP & 1.210 & $1.093-1.339$ & $<0.001$ \\
\hline Complication of atrial fibrillation & 3.315 & $1.145-9.593$ & $<0.05$ \\
\hline \multicolumn{4}{|l|}{ Multivariate analysis } \\
\hline Age (per 1 year increases) & 0.967 & $0.890-1.050$ & $N S$ \\
\hline NYHA functional class & 2.181 & $0.686-6.932$ & $N S$ \\
\hline Creatinine (per 1 SD increases) & 1.116 & $0.695-1.955$ & $N S$ \\
\hline $\mathrm{Na}$ & 0.871 & $0.761-0.996$ & $<0.05$ \\
\hline $\log _{10} B N P$ & 3.500 & $0.974-12.574$ & $N S$ \\
\hline ICTP & 1.210 & $1.013-1.446$ & $<0.05$ \\
\hline Complication of atrial fibrillation & 4.965 & $0.920-26.806$ & $N S$ \\
\hline
\end{tabular}

Abbreviations as in Tables 1,3. 
compared with the degree of decreased PIPC!6-19 In the present study, we focused on collagen degradation rather than collagen synthesis and showed that ICTP, a marker of collagen type I degradation, was useful for determining the prognosis, particularly in HF patients with preserved LV systolic function.

Although the American College of Cardiology/American Heart Association Guidelines state that the diagnosis of diastolic HF is generally based on the finding of typical symptoms and signs in a patient who is shown to have a normal LVEF and no valvular abnormalities on echocardiography, ${ }^{20}$ there are not firm criteria for evaluating ventricular diastolic function at present. Therefore, we defined "HF with preserved LVEF (>50\%)" as preserved LV systolic function in the present study.

BNP is a cardiac neurohormone specifically secreted from the ventricles.21 Elevation of the plasma BNP level is considered to reflect ventricular structural and functional alterations. In addition, experimental studies have demonstrated that cardiac BNP expression is closely associated with LV systolic wall stress in $\mathrm{HF}^{22}$ Although its clinical utility as a biochemical marker of LV systolic dysfunction has been established, ${ }^{23-25}$ it has been also recognized that impaired relaxation and/or compliance per se is not sufficient to trigger cardiac BNP secretion and BNP might be a suboptimal marker of diastolic dysfunction $26-28$ In the present study, BNP displayed a statistically significant correlation with cardiac events in the univariate analysis, but was not an independent predictor in the multivariate analysis of the preserved LV systolic function group. On the other hand, ICTP was an independent predictor of cardiac events by multivariate analysis in the preserved LV systolic function group (Table 5). Furthermore, the AUC of ICTP was much larger in the preserved LV systolic function group than in the reduced LV systolic function group (Fig 4), indicating that ICTP is superior for predicting cardiac events in patients with preserved LV systolic function.

In contrast, ICTP was not an independent predictor of cardiac events in the reduced LV systolic function group (Table 4). Patients with dilated cardiomyopathy and myocardial infarction, most of whom were in the reduced LV systolic function group, suffer from left and/or right ventricular cardiomyocyte damage, leading to progressive cardiac enlargement and accumulation of fibrillar extracellular matrix, a process called cardiac remodeling $29-31$ Our data demonstrated that in the reduced LV systolic function group, cardiac event rates were not significantly different between patients with a high ICTP and those with a low ICTP (Fig 3A). These results suggest that as an index of myocardial stiffness only, ICTP, was not sufficient to stratify cardiac events in the reduced LV systolic function group. In contrast, BNP was a useful marker for risk stratifying HF patients with reduced LV systolic function (Table 4), as reported in many previous studies.

\section{Conclusion}

Although morbidity and mortality rates in diastolic HF are high, clinical markers to predict outcomes have not yet been established. The present study demonstrated the first evidence that the serum level of ICTP at admission may be a promising predictor of prognosis in $\mathrm{CHF}$ patients with preserved LV systolic function.

\section{Acknowledgments}

This study was supported in part by a grant-in-aid for Scientific Research (No. 17590702) from the Ministry of Education, Culture, Sports, Science and Technology, Japan, a grant-in-aid from the 21 st century center of excellence (COE) program of the Japan Society for the Promotion of Science, and grants from Takeda Science Foundation and Fukuda Foundation for Medical Technology.

\section{References}

1. Franklin KM, Aurigemma GP. Prognosis in diastolic heart failure. Prog Cardiovasc Dis 2005; 47: 333-339.

2. Brilla CG, Maisch B, Zhou G, Weber KT. Hormonal regulation of cardiac fibroblast function. Eur Heart J 1995; 16(Suppl): C45-C50.

3. Arimoto T, Takeishi Y, Shiga R, Fukui A, Tachibana H, Nozaki N, et al. Prognostic value of elevated circulating heart-type fatty acid binding protein in patients with congestive heart failure. J Card Fail 2005; 11: $56-60$.

4. Arimoto T, Takeishi Y, Niizeki T, Takabatake N, Okuyama H, Fukui $\mathrm{A}$, et al. Cystatin $\mathrm{C}$ is a novel predictor of cardiac events in patients with chronic heart failure. J Card Fail 2005; 11: 595-601.

5. Niizeki T, Takeishi $Y$, Arimoto $T$, Takahashi $T$, Okuyama H, Takabatake N, et al. A combination of heart-type fatty acid binding protein and brain natriuretic peptide can reliably risk stratify patients hospitalized for chronic heart failure. Circ J 2005; 69: 922-927.

6. Niizeki T, Takeishi Y, Arimoto T, Takabatake N, Nozaki N, Hirono $\mathrm{O}$, et al. Heart-type fatty acid-binding protein is more sensitive than troponin $\mathrm{T}$ to detect the ongoing myocardial damage in chrnonic heart failure patients. J Card Fail 2007; 13: 120-127.

7. Risteli J, Elomaa I, Niemi S, Novamo A, Risteli L. Radioimmunoassay for the pyridinoline cross-linked carboxy-terminal telopeptide of type I collagen: A new serum marker of bone collagen degradation. Clin Chem 1993; 39: 635-640.

8. Hadano Y, Murata K, Liu J, Oyama R, Harada N, Okuda S, et al. Can transthoracic Doppler echocardiography predict the discrepancy between left ventricular end-diastolic pressure and mean pulmonary capillary wedge pressure in patients with heart failure? Circ J 2005; 69: $432-438$

9. Janicki JS, Collagen degradation in the heart. In: Eghbali-Webb M, Editor. Molecular biology of collagen matrix in the heart. Austin, TX: RG Landes; 1995; 61-76.

10. Risteli L, Risteli J. Noninvasive methods for detection of organ fibrosis. In: Rojkind M, Editor. Connective tissue in health and disease. Boca Raton, FL: CRC Press; 1990; 61-98.

11. Gaasch WH, Zile MR. Diastolic dysfunction and diastolic heart failure. Anпи Rev Med 2004; 55: 373-394.

12. Yamamoto K, Masuyama T, Sakata Y, Nishikawa N, Mano T, Yoshida J, et al. Myocardial stiffness is determined by ventricular fibrosis, but not by compensatory or excessive hypertrophy in hypertensive heart. Cardiovasc Res 2002; 55: 76-82.

13. Schwartzkopff B, Fassbach M, Pelzer B, Brehm M, Strauer BE. Elevated serum markers of collagen degradation in patients with mild to moderate dilated cardiomyopathy. Eur J Heart Fail 2002; 4: 439-444.

14. Lombardi R, Betocchi S, Losi MA, Tocchetti CG, Aversa M, Miranda $\mathrm{M}$, et al. Myocardial collagen turnover in hypertrophic cardiomyopathy. Circulation 2003; 108: $1455-1460$.

15. Lindsay MM, Maxwell P, Dunn FG. TIMP-1: A marker of left ventricular diastolic dysfunction and fibrosis in hypertension. Hypertension 2002; 40: 136-141.

16. Lopez B, Querejeta R, Gonzalez A, Sanchez E, Larman M, Diez J. Effects of loop diuretics on myocardial fibrosis and collagen type I turnover in chronic heart failure. J Am Coll Cardiol 2004; 43: 2028 2035.

17. Lopez B, Gonzalez A, Varo N, Laviades C, Querejeta R, Diez J. Biochemical assessment of myocardial fibrosis in hypertensive heart disease. Hypertension 2001; 38: 1222-1226.

18. Laviades C, Varo N, Fernandez J, Mayor G, Gil MJ, Monreal I, et al. Abnormalities of the extracellular degradation of collagen type I in essential hypertension. Circulation 1998; 98: 535-540.

19. Diez J, Panizo A, Gil M, Monreal I, Hemandez M, Pardo Mindan J. Serum markers of collagen type I metabolism in spontaneously hypertensive rat: Relation to myocardial fibrosis. Circulation 1996; 93: $1026-1032$

20. American College of Cardiology/American Heart Association. ACC/ AHA 2005 guideline update for the diagnosis and management of chronic heart failure in the adult: A report of the American College of Cardiology/American Heart Association Task Force on Practice Guidelines (Writing Committee to Update the 2001 Guidelines for 
the Evaluation and Management of Heart Failure). Available at: http://www.acc.org/clinical/guidelines/failure//index.pdf

21. Yasue H, Yoshimura M, Sumida H, Kikuta K, Kugiyama K, Jougasaki $\mathrm{M}$, et al. Localization and mechanism of secretion of B-type natriuretic peptide in comparison with those of A-type natriuretic peptide in normal subjects and patients with heart failure. Circulation 1994; 90: $195-203$.

22. Luchner A, Muders F, Dietl O, Friedrich E, Blumberg F, Protter AA, et al. Differential expression of cardiac ANP and BNP in a rabbit model of progressive left ventricular dysfunction. Cardiovasc Res 2001; 51: 601-607.

23. McDonagh TA, Robb SD, Murdoch DR, Morton JJ, Ford I, Morrison $\mathrm{CE}$, et al. Biochemical detection of left-ventricular systolic dysfunction. Lancet 1998; 351: 9-13.

24. Yamamoto K, Burnett JC Jr, Jougasaki M, Nishimura RA, Bailey KR, Saito Y, et al. Superiority of brain natriuretic peptide as a hormonal marker of ventricular systolic and diastolic dysfunction and ventricular hypertrophy. Hypertension 1996; 28: 988-994.

25. Yamamoto K, Burnett JC Jr, Bermudez EA, Joukasaki M, Bailey KR, Redfield MM. Clinical criteria and biochemical markers for the detection of systolic dysfunction. J Card Fail 2000; 6: 194-200.

26. Von Lukowicz T, Fischer M, Stritzke J, Riegger GA, Schunkert H, Luchner A. BNP as a marker of diastolic function in the general population: Importance of left ventricular hypertrophy. Eur J Heart Fail 2005; 7: 525-531.

27. Mottram PM, Leano R, Marwick TH. Usefulness of B-type natriuretic peptide in hypertensive patients with exertional dyspnea and normal left ventricular ejection fraction and correlation with new echocardiographic indexes of systolic and diastolic function. Am J Cardiol 2003; 92: 1434-1438.

28. Redfield MM, Rodeheffer RJ, Jacobsen SJ, Jacobsen SJ, Mahoney DW, Bailey KR, et al. Plasma brain natriuretic peptide to detect preclinical ventricular systolic or diastolic dysfunction. A communitybased study. Circulation 2004; 109: 3176-3181.

29. Janicki JS. Collagen degradation in the heart. In: Eghbali-Webb M, editor. Molecular biology of collagen matrix in the heart. Austin: Landes; 1995; 61-76.

30. Oie E, Yndestad A, Robin SP, Bornerheim R, Asberg A, Attramadal $H$. Early intervention with a potent endothelin-A/endothelin-B receptor antagonist aggravates left ventricular remodeling after myocardial infarction in rats. Basic Res Cardiol 2002; 97: 239-247.

31. Mori T, Hayashi T, Sohmiya K, Okuda N, Shimomura H, Ohkita M, et al. Mechanisms of combined treatment with celiprolol and candesartan for ventricular remodeling in experimental heart failure. Circ J 2005; 69: $596-602$. 